\title{
Erratum to: Journal of General Plant Pathology
}

Published online: 7 February 2012

(C) The Phytopathological Society of Japan and Springer 2012

\section{Erratum to: J Gen Plant Pathol \\ 77:331-335 (2011) DOI 10.1007/s10327-011-0336-8, 77:342-344 (2011) DOI 10.1007/s10327-011-0337-7, 77:317-325 (2011) DOI 10.1007/s10327-011-0338-6, 77:336-341 (2011) DOI 10.1007/s10327-011-0340-z, 77:326-330 (2011) DOI 10.1007/s10327-011-0342-x}

The original publication of the articles has been erroneously printed with incorrect acceptance dates. The correct dates are given below:

\begin{tabular}{ll}
\hline DOI & Correct acceptance date \\
\hline $10.1007 / \mathrm{s} 10327-011-0336-8$ & 18 August 2011 \\
$10.1007 / \mathrm{s} 10327-011-0337-7$ & 28 August 2011 \\
$10.1007 / \mathrm{s} 10327-011-0338-6$ & 26 August 2011 \\
$10.1007 / \mathrm{s} 10327-011-0340-\mathrm{z}$ & 30 August 2011 \\
$10.1007 / \mathrm{s} 10327-011-0342-\mathrm{x}$ & 15 September 2011 \\
\hline
\end{tabular}

The online version of the original articles can be found under doi:10.1007/s10327-011-0336-8, 10.1007/s10327-011-0337-7, 10.1007/s10327-011-0338-6, 10.1007/s10327-011-0340-z, 10.1007/s10327-011-0342-x. 